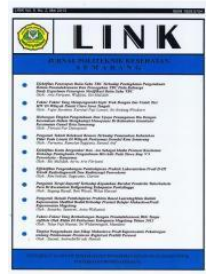

\title{
PENINGKATAN PENGETAHUAN TENTANG GINGIVITIS PADA IBU HAMIL MELALUI KONSELING INDIVIDU
}

\author{
Diyah Fatmasaria* ${ }^{*}$, Nur Farida Lismawati ${ }^{\mathrm{b}}$ \\ a,b Jurusan Keperawatan Gigi; Poltekkes Kemenkes Semarang \\ Jl Tirtoagung, Pedalangan, Kec. Banyumanik, Kota Semarang, Jawa Tengah, Indonesia
}

\begin{abstract}
Abstrak
Mayoritas ibu hamil yang melakukan kontrol ke Puskemas mempunyai karang gigi, dan pengetahuan buruk tentang kebersihan gigi dan mulut khususnya tentang gingivitis Gingivitis adalah penyakit peradangan gusi yang berawal dari adanya plak dan karang gigi. Salah satu cara untuk meningkatkan pengetahuan ibu hamil dengan cara memberikan informasi yang dilakukan secara face to face. Metode yang digunakan yaitu metode eksperimen semu dengan rancangan pre-test dan post-test. Subjek sebanyak $44 \mathrm{ibu}$ hamil yang dibagi menjadi dua kelompok, keduanya mendapatkan penyuluhan tentang gingivitis di awal pertemuan. Analisa data menggunakan uji paired $t$-test dan uji independent $t$-test. Uji independent $t$-test menunjukan hasil perbedaan yang bermakna antara kelompok perlakuan dan kelompok kontrol dengan nilai $p=0,019 \quad(<0,05)$. Pemberian konseling secara face to face efektif untuk meningkatkan pengetahuan tentang gingivitis pada ibu hamil di Puskesmas Karangtengah Kabupaten Demak.
\end{abstract}

Kata Kunci: Ibu Hamil, Konseling secara face to face.

\begin{abstract}
[IMPROVEMENT OF KNOWLEDGE ABOUT GINGIVITIS IN PREGNANT MOTHER THROUGH INDIVIDUAL COUNSELING] The majority of pregnant women who control to Primary Health Centre have tartar, and poor knowledge about oral and dental hygiene especially about gingivitis. Gingivitis is an inflammatory gum disease that starts with plaque and tartar. One way to increase the knowledge of pregnant women is by providing information which done face to face. The method used was a quasi-experimental method with a pre-test and post-test design. Subjects were 44 pregnant women who were divided into two groups, both of whom received counseling about gingivitis at the beginning of the meeting. Data analysis used paired t-test and independent $\mathrm{t}$-test. Independent $\mathrm{t}$-test showed a significant difference between the treatment and control groups with a $\mathrm{p}$ value of $0.019(<0.05)$. Face to face counseling is effective for increasing knowledge about gingivitis in pregnant women at the Karangtengah Health Center in Demak Regency.
\end{abstract}

Keywords: Pregnant women, counseling face to face.

\section{Pendahuluan}

Pada masa kehamilan terjadi perubahanperubahan pada ibu hamil seperti perubahan

*) Correspondence Author (Diyah Fatmasari)

E-mail: fatmasaridiyah@gmail.com fisiologis dan perubahan psikis. Oleh sebab itu, menjaga kesehatan tubuh termasuk menjaga kesehatan gigi dan mulut menjadi sesuatu yang mutlak dilakukan oleh ibu hamil (Novianto, 2010).

Perawatan kesehatan gigi dan mulut 
sebelum masa kehamilan merupakan bagian dari perawatan kesehatan secara keseluruhan. Pada saat kehamilan terjadi perubahan hormon pada ibu. Perubahan hormon pada saat kehamilan sangat mempengaruhi kondisi rongga mulut ibu hamil. Perubahan hormon ini seringkali disertai dengan adanya faktor lokal yang ada di rongga mulut seperti plak dan karang gigi. Keadaan tersebut akan diperparah dengan adanya kondisi gigi dan mulut yang buruk sebelum kehamilan (Kementrian Kesehatan RI, 2012).

Faktor hormonal pada saat kehamilan mampu memperburuk kondisi rongga mulut apabila tidak dijaga kebersihannya. Keadaan tersebut mampu mempengaruhi terjadinya gangguan pada jaringan periodontal serta mempengaruhi timbulnya penyakit gigi dan mulut seperti gingivitis (Novianto, 2010).

Gingivitis merupakan penyakit jaringan periodontal yaitu tepi gingiva yang berwarna kemerahan sampai merah kebiruan, pembesaran kontur gingiva karena edema dan mudah berdarah (Andriyani dkk, 2014). Ini disebabkan oleh indikator kebersihan gigi dan mulut yang buruk. Ditandai dengan adanya plak dan karang gigi. Plak yang dibiarkan dan tidak dibersihkan akan semakin tebal dan dalam waktu satu jam akan membentuk pelikel, selaput lendir dari ludah yang menyelimuti gigi (Fatmasari dkk, 2014). Semakin lama plak tidak dibersihkan maka menyebabkan tepi gingiva berwarna kemerahan sampai merah kebiruan dan pembesaran kontur gingiva karena edema dan mudah berdarah. Peradangan ini terjadi pada ibu hamil dengan adanya peningkatan produksi hormon serta mampu menyebabkan iritasi lokal dikarenakan gingiva merespon secara berlebihan (Hidayati dan Rahayu, 2012).

Peningkatan hormon estrogen dan progesteron dapat meningkatkan resiko terkena radang gusi atau gingivitis pada saat kehamilan yaitu gingivitis kehamilan. Gingivitis kehamilan (Pregnancy gingivitis) merupakan radang gusi yang dialami pada masa kehamilan yang disebabkan oleh kurangnya kesadaran menjaga kebersihan gigi dan mulut.

Prevalensi gingivitis di Indonesia menduduki peringkat kedua yang menunjukan angka 96,58\%., sedangkan di Jawa Tengah sebesar 25,8\% (Kementrian Kesehatan, 2018). Pada studi dari Agustina dkk (2018) menyimpulkan sebagian besar ibu hamil di Puskesmas Kaliwungu atau 49\% ibu hamil mengalami kebersihan gigi dan mulut yang buruk dan $70 \%$ ibu hamil mengalami gingivitis kategori ringan. Dari studi pendahuluan yang dilakukan, di beberapa desa di kecamatan Karangtengah kabupaten Demak, seperti desa Dukun, Klitih dan Karangtowo sebanyak 56 dari total 86 ibu hamil atau sekitar $65,1 \%$ mempunyai karang gigi. Bahaya yang ditimbulkan dari gingivitis selama kehamilan adalah terjadinya risiko 8,75 kali kelahiran berat badan lahir rendah (BBLR) pada bayi (Retnoningrum, 2006).

Tingginya angka penderita gingivitis pada ibu hamil maka diperlukan upaya untuk mencegah gingivitis. Salah satunya yaitu mengurangi makan makanan kariogenik serta menggosok gigi dengan benar dan teratur. Upaya lain yang dapat dilakukan oleh tenaga kesehatan yaitu dengan memberikan edukasi kepada ibu hamil untuk meningkatkan pengetahuan mereka mengenai penyakit gingivitis. Salah satu caranya yaitu dengan memberikan konseling (Kementrian Kesehatan RI, 2012).

Pengetahuan merupakan salah satu indikator penting bagi ibu hamil dalam menjaga kebersihan gigi dan mulutnya. Kurangnya pengetahuan akan mempengaruhi kondisi kesehatan gigi dan mulut yang mampu mempengaruhi kenyamanan pada ibu hamil. Cara terbaik meningkatkan pengetahuan khususnya tentang kesehatan gigi dan mulut yaitu dengan melakukan pendidikan kesehatan.

Menurut Muffidah dkk (2016), salah satu pendidikan kesehatan yang terbukti efektif untuk meningkatkan pengetahuan ibu hamil adalah dengan cara konseling. Konseling merupakan salah satu media informasi yang mampu memberikan informasi baru pada ibu hamil. Kegiatan ini dilakukan untuk memberikan bantuan kepada klien dalam membuat suatu keputusan atau memecahkan masalah serta dilakukan agar dapat mencapai tujuan tertentu. Dalam hal ini konseling yang dilakukan ialah antara konselor (perawat gigi) kepada klien (ibu hamil).

Berdasarkan hasil wawancara oleh peneliti saat studi pendahuluan, lebih dari $50 \%$ ibu hamil yang berkunjung di Puskesmas Karangtengah Kabupaten Demak mempunyai tingkat pengetahuan yang buruk tentang kebersihan gigi dan mulut khususnya tentang gingivitis.

\section{Metode}

Metode yang digunakan quasi eksperimen dengan desain pre-test dan post-test group. 
Subjek adalah ibu hamil Puskesmas Karangtengah Kabupaten Demak sebanyak 44 orang yang dibagi menjadi dua kelompok yaitu kelompok perlakuan dan kelompok kontrol. Kelompok perlakuan sebanyak 22 ibu hamil yang diberikan konseling secara face to face dan dan kelompok kontrol yaitu 22 ibu hamil tidak diberikan konseling secara face to face. Kedua kelompok diberikan penyuluhan tentang gingivitis di awal pertemuan. Teknik pengambilan sampel yaitu Accidental Sampling Instrumen penelitian yang digunakan ialah lembar kuesioner yang diisi oleh responden

Analisa hipotesis menggunakan uji Paired tTest untuk mengetahui tingkat pengetahuan ibu hamil sebelum dan sesudah konseling secara face to face. Selanjutnya dilakukan uji Independent Sample t-Test untuk mengetahui efektivitas konseling secara face to face dalam meningkatkan pengetahuan ibu hamil.

\section{Hasil dan Pembahasan}

a. Hasil analisis univariat

Tabel 1. Distribusi frekuensi pengetahuan ibu hamil sebelum dan sesudah konseling secara face to face.

\begin{tabular}{lllll}
\hline \multirow{2}{*}{ Kriteria } & \multicolumn{2}{c}{ Sebelum } & \multicolumn{2}{c}{ Sesudah } \\
\cline { 2 - 5 } & $n$ & $\%$ & $n$ & $\%$ \\
\hline Baik & 3 & 14 & 9 & 41 \\
Sedang & 7 & 32 & 8 & 36 \\
Kurang & 12 & 55 & 5 & 23 \\
Jumlah & $\mathbf{2 2}$ & $\mathbf{1 0 0}$ & $\mathbf{2 2}$ & $\mathbf{1 0 0}$ \\
\hline
\end{tabular}

Tabel 1 menunjukkan pengetahuan ibu hamil sebelum diberikan konseling secara face to face tentang gingivitis, presentase yang paling tinggi adalah tingkat pengetahuan dengan kriteria kurang yaitu sebesar 55\%. Sedangkan pengetahuan sesudah diberikan konseling secara face to face tentang gingivitis, presentase paling tinggi adalah pengetahuan dengan kriteria baik yaitu sebesar $41 \%$.

Tabel 2. Distribusi frekuensi pengetahuan ibu hamil kelompok kontrol sebelum dan sesudah penyuluhan.

\begin{tabular}{lllll}
\hline \multirow{2}{*}{ Kriteria } & \multicolumn{2}{l}{ Sebelum } & \multicolumn{2}{l}{ Sesudah } \\
\cline { 2 - 5 } & $n$ & $\%$ & $n$ & $\%$ \\
\hline Baik & 2 & 9 & 2 & 9 \\
Sedang & 9 & 41 & 10 & 45 \\
Kurang & 11 & 50 & 10 & 45 \\
\hline Jumlah & $\mathbf{2 2}$ & $\mathbf{1 0 0}$ & $\mathbf{2 2}$ & $\mathbf{1 0 0}$ \\
\hline
\end{tabular}

Berdasarkan tabel 2 dapat dilihat bahwa pengetahuan ibu hamil pada kelompok kontrol sebelum penyuluhan yang memperoleh presentase paling tinggi adalah pengetahuan dengan kriteria kurang sebesar 50\%, sedangkan pengetahuan pada saat sesi kedua (sesudah), tidak ada perubahan pada jumlah pengetahuan dengan kriteria baik.

\section{b. Hasil Analisis Bivariat}

Berdasarkan uji normalitas dengan Shapiro Wilk didapatkan hasil data berdistribusi normal.

Tabel 3. Hasil uji beda nilai sebelum dan sesudah konseling pada kelompok perlakuan dan kontrol

\begin{tabular}{lll}
\hline Pengetahuan & Kel. Perlakuan & Kel. kontrol \\
\hline Sebelum & $0,000^{*}$ & 0,167 \\
Sesudah & & \\
\hline
\end{tabular}

Berdasarkan tabel 3 diatas dapat dilihat bahwa hasil dari uji paired t-test kel perlakuan terdapat perbedaan yang signifikan pada nilai sebelum dan sesudah konseling secara face to face terhadap pengetahuan tentang gingivitis pada ibu hamil. Sebaliknya pada kelompok kontrol menunjukkan nilai tidak signifikan sehingga tidak ada perbedaan pengetahuan sebelum dan setelah penyuluhan massal

Tabel 4. Hasil uji Independent t-Test rata-rata pengetahuan ibu hamil pada kelompok perlakuan dan kelompok kontrol.

\begin{tabular}{lll}
\hline Variabel & p-value & Interpretasi \\
\hline $\begin{array}{l}\text { Perlakuan } \\
\text { Kontrol }\end{array}$ & 0,019 & Ho ditolak \\
\hline
\end{tabular}

Tabel 4 diatas menunjukkan hasil uji statistik dengan uji Independent $t$-Test didapatkan nilai p-value 0,019 (< 0,05) menunjukan ada perbedaan yang signifikan antara pengetahuan ibu hamil pada kelompok perlakuan yang diberikan konseling face to face dengan kelompok kontrol yang diberikan penyuluhan secara massal (dikumpulkan bersama-sama).

Perubahan pengetahuan responden dikarenakan proses konseling dilakukan secara tatap muka langsung dengan responden. Responden juga dapat menanyakan secara langsung materi yang belum jelas dan belum dipahami. Proses konseling berlangsung dengan baik, responden merasa lebih nyaman karena dengan dilakukan konseling dengan tatap muka, peneliti dapat menjalin keakraban yang 
lebih intens dengan responden. Hal-hal yang ingin ditanyakan oleh responden juga akan lebih terjaga kerahasiaannya.

Petrus (2016) menerangkan bahwa keberhasilan proses konseling terkait dengan dua hal utama yaitu karakteristik konselor dan karakteristik klien. Konselor harus mampu menjalin hubungan baik dengan klien sedangkan klien mempunyai motivasi atau kemauan dan kemampuan untuk mengubah dirinya menjadi lebih baik. Menurut Fatmasari, dkk (2014) motivasi merupakan keinginan manusia yang terkait dengan psikologi seperti sikap, pemintaan dan tindakan. Motivasi merupakah salah satu faktor yang penting karena mampu mendisitribusikan, mendukung psikomotor manusia untuk bekerja keras agar mendapat hasil yang optimal dalam usahanya.

Berbeda dengan kelompok yang diberikan konseling secara face to face dimana responden atau ibu hamil diberikan informasi pengetahuan tentang gingivitis dengan konseling secara tatap muka langsung dengan konselor yang sebelumnya juga sudah mendapatkan informasi melalui penyuluhan bersama dengan kelompok kontrol. Sedangkan ibu hamil pada kelompok kontrol hanya mendapatkan informasi melalui penyuluhan saja.

Penelitian berlangsung kondusif dan dapat diamati bahwa responden terlihat antusias pada saat sebelum diberikan penyuluhan, namun merasa jenuh pada saat mengerjakan kuesioner dengan jarak 2 hari sesudah diberikan penyluhan. Menurut Sufiyah (2014) kejenuhan berarti padat, penuh atau bosan yang mengakibatkan tidak dapat memproses informasi-informasi dan menghambat kinerja atau kegiatan yang sedang dilakukan terutama melakukan pekerjaan yang sama dalam beberapa kali. Kejenuhan mengisi kuesioner dikarenakan mereka hanya mendapat informasi atau pengetahuan dari penyuluhan saja.

Terjadinya sedikit peningkatan pengetahuan responden kelompok kontrol yang tidak diberikan konseling secara face to face dikarenakan jarak waktu antara mengerjakan kuesioner sebelum dan sesudah yaitu 2 hari yang memungkinkan kelompok kontrol (ibu hamil) terpapar informasi terkait penyakit gingivitis dari berbagai media yang diluar kendali peneliti sehingga memungkinkan ibu hamil sedikit lebih tahu dan mampu menjawab beberapa pertanyaan kuesioner yang sebelumnya tidak bisa dijawabnya (Muffidah $\mathrm{dkk}, 2016$ ).

\section{Kesimpulan dan Saran}

Konseling secara face to face lebih efektif untuk meningkatkan pengetahuan ibu hamil dibandingkan dengan cara penyuluhan massal (bersama-sama). Saran sebaiknya para kader jika melakukan konseling secara pribadi dipanggil satu persatu.

\section{Ucapan Terima Kasih}

Terima kasih disampaikan kepada para responden yang sudah meluangkan waktu untuk menerima konseling dan pemeriksaan rongga mulut.

\section{Daftar Pustaka}

Agustina YI, Fatmasari D dan Supardan I. 2018. Hubungan Usia Kehamilan, dan Tingkat Kebersihan Gigi dan Mulut dengan Kejadian Gingivitis pada Ibu Hamil di Wilayah Kerja Puskesmas Kaliwungu Kendal Tahun 2018. Semarang: Skripsi JKG Poltekkes Kemenkes Semarang.

Andriyani PD, Apriasari M, Putri 2014. Studi Deskripsi Kelainan Jaringan Periodontal pada Wanita Hamil Trimester 3 di RSUD Ulin Banjarmasin. Dentino Jurnal Kedokteran Gigi. 2(1): 95-101

Fatmasari, D, Mustafa S, Santoso B, 2014, Efektivitas Buah Bit (Beta Vulgaris) sebagai Disclosing Solution (Bahan Identifikasi Plak. Semarang: ODONTO Dental jurnal, 1(2): 6-9

Fatmasari, D, Saadah L, 2014. Perbedaan Motivasi Anak, Remaja dan Dewasa pada Pasien Orthodontic Dental Care. Semarang: Kemas Jurnal, 10(1): 21-24

Heru, R, Hakimi M, 2012. Konseling Ibu Hamil pada Bidan Praktik Swasta dan Puskesmas di Kabupaten Bantul. Yogyakarta: Jurnal Kebijakan Kesehatan Indonesia 3(2): 168-172

Hidayati, K, Rahayu G, 2012. Pengaruh Kebersihan Gigi dan Mulut Dengan Status Gingivitis Pada Ibu Hamil di Wilayah Kerja Puskesmas Andalas Kecamatan Padang Timur Kota Padang. Majalah Kedokteran Andalas, 36(2): 216-224

Kementrian Kesehatan RI, 2012, Pedoman Pemeliharaan Keshatan Gigi Dan Mulut Ibu Hamil Dan Anak Usia Balita Bagi Tenaga Kesehatan Di Fasilitas Pelayanan Kesehatan, Jakarta.

Kementrian Kesehatan RI, 2018, hassil Utama Riskesdas 2018, available at http://www.kesmas.kemkes.go.id/assets/ 
upload/dir_519d41d8cd98f00/files/Hasilriskesdas-2018_1274.pdf

Mufiddah I, Paramastri I, dan Agung WT, 2016, Efektivitas Konseling untuk Meningkatkan ASI Eksklusif pada Ibu Hamil di Tenggarong, Kutai Kartanegara. Berita Kedokteran Masyarakat. 32(4): 133-138

Novianto 2010. Manajemen kesehatan gigi pada kehamilan. Solo: Skripsi Kedokteran Universitas Negeri Solo.

Petrus, Jerizal, 2016, Kajian Konseptual Hubungan Terapeutik dan Faktor-Faktor yang Mempengaruhi Keberhasilan Proses
Konseling. Jurnal Inovasi Pembelajaran Karakter (JIPK), 1(2): 1-10

Retnoningrum, D, 2006. Gingivitis pada Ibu Hamil sebagai Faktor Resiko Terjadinya Bayi Berat Badan Lahir Rendah Kurang Bulan di RS. Dr. Kariadi Semarang. Dentika dental journal. Vol 1: 1-8

Sulfiyah, L. T, 2014. Hubungan antara Presepsi terhadap Kebisingan dengan Kejenuhan Belajar Siswa di Kawasan Industri. Surabaya: Skripsi Universitas Islam Negeri Sunan Ampel Surabaya. 